\title{
Integrated Curriculum for a Saudi University EAP Class
}

\author{
Sami Al-wossabi \\ English Department, Faculty of Arts and Humanities, Jazan University, Saudi Arabia
}

\begin{abstract}
In the present paper an integrated curriculum project is developed specifically for Saudi EFL students enrolled in in an EAP course with the goal of pursuing their higher studies of English major at an American university. The purpose is to provide a comprehensive description of the proposed integrated curriculum with an aim for enabling the targeted Saudi students get a true picture of English as a unified whole rather than segregated skills. Being exposed to authentic language, Saudi students are challenged to act, think and react naturally in the language while developing self-awareness on how to meaningfully and purposefully interact with others. The proposed curriculum is, therefore, designed to teach the four skills in a coherent way and to be practiced together with no clear preference of one skill upon the other. Further, the instructor of the course is involved in the process of collecting necessary information via surveys, questionnaires and interviews, stating goals and objectives and selecting appropriate authentic materials.
\end{abstract}

Index Terms-EAP class, integrated curriculum, authentic materials, needs analysis, thematic content

\section{INTRODUCTION}

Of late, integrated curricula following an integrated teaching approach has been the focus in the acquisition of knowledge of foreign languages (Drake \& Burns,2004; Fogarty \& Stoehr,1995; MacMath, Wallace \& Chi, 2009; Paterson, 2003; Pring, 2006). The tendency is to enable foreign learners of English understand the richness and complexity of language and that it is a medium of thoughts, feelings and communication rather than isolated discrete items (Oxford, 2001).

EFL situation in Saudi Arabia is not far from the rest of the world where English is mostly perceived and taught as separate chunks of linguistic and grammatical knowledge. A classic example of the segregation of language can be seen in the distribution of language skill courses at the university level for students majoring in English (e.g., writing1 \& 2 , reading $1 \& 2$, listening and speaking $1 \& 2$, etc.).

The researcher observed that many EFL Saudi students perceive these skills as separate entities and as such cannot easily process related information holistically in their spoken or written discourse. This is probably why EFL Saudi students when sent abroad to pursue their higher studies are required to study one year in an intensive English program ahead of their degree course.

Although the proposed curriculum is set to be taught within a short period of time, it is hoped that it will enable students understand the mechanisms underlying the proper use of the naturally occurring speech of everyday life situations. Further, the instructor selected for this course is a Saudi native like speaker of English who have completed his MA in English studies from an American university. This will provide more credibility to the course and expectantly instigate higher motivation on the part of the students.

\section{STEPS FOR DEVELOPING EAP CURRICULUM}

\section{A. Parameters for the Teaching Situations}

This proposed curriculum is designed for EFL Saudi teaching assistants who are enrolled in a language class ahead of studying in the US. Based on the administration nominations, teaching assistants are selected to pursue higher studies at American universities. Over a period of one month, the class will meet every day, Sunday through Thursday, for two hours duration. Most of the students are at the end of their twenty years of age. All have graduated with a bachelor's degree from different fields of study and are classified as having higher intermediate level.

Despite the fact that for many students the ability to communicate in English is somehow limited, they are able to read or write fairly well. However, some have better speaking and listening skills than others. They are all highly motivated, and enthusiastic about the class. The classroom has a board, general English textbooks, supplementary materials for all the students, and a special material providing interactive extracurricular activities for the instructor. There is a language lab with a television, headphones, and 10 computers with English learning software.

\section{B. Needs Analysis}

A thorough needs analysis is to be carried out to determine students' needs, desires, lacks, and the amount of exposure they have had to English language. As the students will be in an academic setting, their university needs are 
likely to be the most important. They will need a wide collection of skills to excel in their new learning environment. A needs analysis is set to speculate on how to teach and learn these necessary skills. It is also an on-going process that is subjected to change and revaluation during the course in case that some skills are misidentified or underrepresented. As Kumaravadivelu (2001) suggested, trialing is a fundamental part of teaching if teachers lack the means to use their classroom experiences for curriculum development.

Obtaining samples of students current writing composition, test data, or examples of the kind of writing assignments is a more concrete way to find out more about students' problems and needs (Richards, 2001). A corpus analysis of language in use at American Universities, would be extremely helpful to familiarize Saudi EFL students with everyday occurring speech among American university students. Having access to data of real-life, on-campus language use, would help the instructor in planning exercises designed to imitate the types of naturally occurring exchanges. The types of information obtained via corpus analysis will reflect actual language used by actual people inside and outside the classroom. This can provide a rich context of real English to the instructor while preparing students for the new experience of studying abroad.

Saudi students before sent abroad usually contacted other Saudis' with the intention to accompany them upon arrival and stay with them at least for the first three months if not more. This is because of their attempt to avoid any inconveniences and embarrassments that could result from their lacking of communication skills necessary to survive in a new community. Therefore, off-campus experiences need to be integrated in the proposed curriculum in this project. Everyday tasks such as service encounters are key to their success and happiness in the new environment.

Other procedures that can be used to identify the students' needs, and lacks may include questionnaires, interviews, and self-analyses. Questionnaires and interviews are effective sources of eliciting information about student experiences with language use, perceptions and attitudes of the learning processes (Tarone, 1989; West, 1997). Interviews, for example, may allow for clarification and more details in case some areas are not covered in the questionnaire. Selfanalyses can be used to define how students view their proficiency in L2 skills and subskills.

This project develops mainly two different surveys (See Appendices A and B) to obtain information from two different sources and ensure valid and precise responses elicited from students. The first survey (Appendix A) is designed for international Saudi students who are currently studying in the United States, or who have recently been there. This survey needs to be done prior to the course. The information obtained will purposefully be manifested in devising extracurricular activities as supplementary materials. The aim is to detect the skills and/or tasks these students found they were well-prepared for, somewhat prepared for, or under-prepared for upon their enrollment in language classes. The survey has a box to tick for each of these three choices next to each skill/task. The survey statements include skills such as listening to American pronunciation, writing essays, and communicating effectively with peers outside the class.

One limitation to this survey is the difficulty of obtaining responses from students currently studying in the United States considering that the researcher resides in Saudi Arabia. It is also possible that respondents may fill out the survey without much thought as they are not part of the present learning situation. To minimize such effect, the survey is to be handed to a trusted friend or teacher in the USA to carry out the survey.

Further, the process of obtaining information from international Saudi students can be viewed as an ongoing process and as such it would rather be more methodical to utilize such information in devising extracurricular activities. This type of survey can truly be a good sustainable source for backing up the existing activities for this proposed curriculum.

The second survey featuring self-rating questions is meant for the targeted students of the present class project. It addresses previous and current experiences with English, inside and outside the classroom. It asks questions such as how long they have been studying English, how many hours of instruction given per week, what skills were taught, and what skills they are good at the most. To lessen the ambiguity that may arise while filling out the survey and to get more precise answers, students will check the line below the question that most closely answers the question. There is also an open-ended question at the end of the survey which is designed to report on any previous studying or travelling experiences to an English-speaking country.

Such survey is designed to elicit more precise account of what experiences the students have had with English, and to appraise their further language needs. Richards (2001) claimed that self-rating can be imprecise since students might rate themselves impressionistically as high or low in their current state of language skills proficiency. Thus, short interviews with students are to be conducted to compensate for any undetermined responses and to help identify students' language abilities. Other practices to be added are reflective observations which can be manifested throughout the course (Richards 1990; Farrell 2012).

As stated above, the information obtained from needs analyses is an ongoing processes that could be supplemented before, during or after the course. Such processes are necessary for the sustainable improvement of the syllabus as no one knows what could be changed or need to be changed when the instructor begins teaching the language class.

\section{Situation Analysis}

In Saudi Arabia, EFL students might either be skeptical or/and cautious of any approaches that drifts them away from traditional approaches of learning. Students may not feel comfortable being asked to engage in communicative tasks with peers as most of them are used to be passive in traditional classrooms that mostly feature teachers' centeredness. 
Despite these dogmas, the students are expected to be very motivated since they view studying in an English speaking country as a venerable and valuable opportunity.

Yet, the administration might question the advantages of incorporating student one to one interaction approach while underrepresenting the teaching of grammar in the present project. Some faculty members' views, those in favor of grammar oriented approaches, may also pose a threat towards the incorporation of such communicative tasks. Overall, it is indeed the responsibility of the researcher to explain his stance to all those concerned in the learning situation where the present EAP curriculum is to be implemented. Explaining, to administrators and faculty members, the advantages of integrating the teaching of language skills, and the learning goals and outcomes of the proposed course should rather bring about a vision not a threat. Meeting with those concerned above should change the assumed status quo, ease the administrative and academic issues that may arise, and serve the ultimate goal of enhancing Saudi students' language abilities.

It is worth mentioning here that Jazan University does have many utilities and resources, though somehow, not as those available in American universities. For instance, the library is relatively small and does not include particular communicative language texts. However, upon request, the administration can equip a particular class with all necessary equipment needed for this particular interactive class, such as, computers, data show, textbooks etc. This is a privilege that is much more than many institutions around could handle. Thus, we can safely acclaim that with regard to the situational factors the positive factors outweigh the negative ones in this EFL context.

\section{Goals and Objectives}

As mentioned above, Saudi students preparing to study in American universities are in great need to be equipped with an array of academic as well as social skills to survive in and off campus. As a result for these basic needs, the goals and objectives for this EAP course are divided into separate categories for academic reading and writing, academic speaking and listening, social speaking and listening, content, strategy, and study skills.

The following are general goals and objectives that are basic and should be addressed at any EAP language course preparing L2 students for their future academic endeavor. Besides, the sustainable information supplemented by the needs analysis will reinforce and support the accomplishment of the proposed goals.

\section{Academic Reading and Writing}

Goal: Understanding key ideas and details of academic texts, newspaper, magazine articles, and website texts.

Objectives: Students will be able to:

- demonstrate comprehension of academic texts

- summarize, explain, or paraphrase academic texts.

- skim and scan academic texts for main ideas.

- understand vocabulary items while reading

- use contextual clues to facilitate comprehension.

Goal: Reading beyond word-level meanings.

Objective: Students will be able to:

- Interpret indirect meanings mentioned in the text.

Goal: Communicating ideas and information via writing.

Objectives: Students will be able to:

- compose and organize written composition and convey information properly and intelligibly.

- use a variety of vocabulary items.

- use complex grammatical structures required in academic writing.

\section{Academic Speaking and Listening}

Goal: Understanding lectures.

Objectives: Students will be able to:

- follow up topics, arguments, and other issues of lectures.

- extract important information and ideas.

Goal: Participating intelligibly in class, group discussions and presentations.

Objectives: Students will be able to:

- express their thoughts and ideas

- summarize, rephrase, or explain a particular concept verbally

- understand what others are saying.

- use clarification strategies to communicate more effectively.

\section{Social speaking and listening}

Goal: Communicating competently in everyday real life situations in the target culture.

Objectives: Students will be able to:

- understand and participate in everyday conversations in English using language functions such as requests, complaints, greeting, and giving/following directions.

- understand the language used in service encounters and other common situations (e.g., at the cafeteria, bookstore, bank).

- understand a casual conversation between two native-speakers. 
- use clarification strategies to communicate more effectively.

\section{Content}

Goal: Understanding different aspects of American history and culture.

Objectives: Students will be able to:

- read, write, and talk about famous American characters, customs, and social activities.

- locate major regions, states, and cities in the United States using maps.

- read, write, listen and talk about aspects of American movies and music.

- read, write, listen and talk about aspects of American universities such as programs, classes, and extra-curricular activities.

\section{Strategy}

Goal: Negotiating learning goals and evaluating learning progress.

Objectives: Students will be able to:

- recognize success or failure in their subsequent learning,

- find out what they need to improve.

Goal: Using a variety of strategies to facilitate learning.

Objectives: Students will be able to:

- use cognitive, metacognitive, and social affective strategies.

- use clarification strategies to communicate more effectively.

Goal: Using a bilingual and an English-to-English dictionary efficiently.

Objective: Students will be able to:

- recognize headwords in bilingual and English-to-English dictionaries to help them in reading articles and writing papers.

Goal: Using resources to facilitate the composition processes.

Objective: Students will be able to:

- use resources such as dictionaries, encyclopedia, and other reference guides to write compositions.

\section{Study skills}

Goal: Reading and understanding graphs, maps, and charts

Objective: Students will be able to:

- summarize the main points of a diagram, graph, table or chart.

Goal: Understanding how to take different types of objective and subjective testing items

Objectives: Students will be able to:

- respond to multiple-choice, short answer, and true-false items in a timely manner.

- understand rubrics and prompts in a test.

Goal: Using PCs, laptops, and mobile technologies for academic purposes.

Objective: Students will be able to

- use word processing, e-mail, and other computer programs to complete class assignments.

The above goals and objectives are also subjected to change and adjustment in response to the students' needs in case some skills are underrepresented or misidentified.

\section{Specification of Syllabus Framework AND Course CONTENT}

The syllabus framework chosen for this EAP course will be built around a thematic content featuring skills-based emphasis with a lexical component. A content-based syllabus will lend itself easily to the integrated teaching of the four traditional language skills (Brinton, 2007; Brinton, Snow, and Wesche, 1989; Mohan, 1986; Reynolds, 2015; Valeo, 2013). As Stoller (2002) suggested, "In a content-based approach, the activities of the language class are specific to the subject matter being taught, and are geared to stimulate students to think and learn through the use of the target language" (P.2). The main principle of such approach is that instructed language classroom should lead to natural use of language based on collaborative knowledge building (Ellis, 2003; Pawan, \& Ortloff, 2011; Swan, 2005; Wesche, 2010; Wesche \& Skehan, 2002)

This type of syllabus provides a scope for students to listen to and speak about the content and read and write assignments related to the content. The topics covered in this content based syllabus will address aspects of the American culture and university life which will ease their learning and residency in the new environment. Thus, the emphasis is to expose students to a "highly contextualized" second language environment by using the subject matter as the content of language learning" (Wesche \& Skehan, 2002, p. 220). Another reason for selecting content-based instruction is that it embraces the use of authentic materials, which is highly expected to prepare students for their future "real-life" experiences (Brinton, Snow, and Wesche, 1989; Coyle, Hood, \& Marsh, 2010; Early, 2001; Mohan, 1986; Valeo, 2013).

In this syllabus, the skills will be embedded in the content. For example, students will be taught important reading skills necessary at the university such as, selecting relevant information, finding main ideas, and identifying the meaning relationships between the words and ideas. Writing skills and subskills will involve activities such as, creating a topic sentence, taking notes, summarizing, and reflective writing. Listening involves listening for essential factual 
information, listening for association and evaluation in the lecture, and reprocessing information from a lecture using notes. Using clarification strategies, recognizing turn-taking signals, participating in seminars, giving academic presentations are among many speaking tasks designed to foster students produce oral output. All the language skills will mostly be presented through subskills to lessen the cognitive load on the part of the students so that the tasks in hands are more achievable and can be successfully accomplished.

The building of vocabulary repertoire is critical and necessary for students preferably before joining a foreign university. Thus, a subdivision of the content based syllabus will entail a lexical component which is to be used as an aspect of a more comprehensive syllabus (Richards, 2001). Through introducing students to multiple genres, students will be exposed to a variety of vocabulary items specific for academic lectures and writing, as well as that of other lessformal registers such as service encounters and study groups. The use of corpus of naturally occurring speech used on and off campus would facilitate this purpose and would rather eliminate chances of wasting time while teaching less frequent words to students.

The course thematic content aims at familiarizing the students with their future host country and social and academic life abroad through the use of related social and cultural topics. Such topics are thought to keep students motivated throughout the course as they are useful and more importantly relevant to their needs and desires. Richards and Rodgers (2001) stated that the more interesting and useful the information presented in the course content, the better and faster the processes of acquisition would be. Liuoliene and Metiuniene (2006) considered that learners' needs are essential "driving force" in the acquisition of L2.

Hence, the thematic content of the course is to be presented through topics about studying at American universities and American social and cultural life. The American university part in the proposed syllabus will include topics about American campus life, covering issues such as classes, sports, teachers and other events along with extra-curricular activities. The material for this section will in part incorporate information from university web pages used for international students. Saudi graduate students' experiences at American universities will also be a part of this section. The American life subdivision of the content will focus on aspects such as music, movies, history, and U.S-Saudi relations.

\section{Materials DeVelopment/SAmPle LeSson Plan}

All lesson plans in this language course will address the students' needs, and aim to carry out the course's goals and objectives. They also follow the content-based syllabus as the predominant syllabus along with skills and the lexical components for the course (See Appendix C). The lesson plan in appendix C is a sample plan that represents the types of lesson plans and activities to be used in this course. All the activities devised for the lesson plan will interactively address the four language skills. The lesson plan is a topic chosen from the American university subdivision of the course, which educates the students about their future environments.

The sample lesson plan is structured around an authentic university text from an American University's "International students" website. The type of discourse in this text is chosen to familiarize students with the type of expository written information offered by the office of international students. The warm up activity will ask students to think of the types of university-provided services or tasks that they might need to perform before and after joining an American university.

In the first activity, students will be trained on reading and interpreting different texts._Speaking skills is manifested through the discussion of these different issues where students are given chances to reflect upon their understanding of these expository texts.

The characteristics of the organization of expository texts will also be discussed (e.g. introduction, body of the text, conclusion, main ideas, etc.) which will in turn help them compose written information appropriately and comprehensibly.

Activity two employs the same text. Yet the focus is on paraphrasing where students will read and use the explanatory text as a resource to facilitate the learning and composition processes. This activity is part of the skillsbased component of the syllabus as students will be using the specific writing subskill of paraphrasing. Furthermore, working in pairs/group discussion while using the target language allows the students to practice speaking and listening intelligibly in class. Thus, this activity allows for the integration of all four skills: reading, writing, speaking, and listening. The lesson ends with a closure activity that reviews the processes of organization and paraphrasing of expository prose.

\section{CONCLUSION}

The present project develops an integrated language syllabus at the level of whole language development and allskills integration and at the level of interdisciplinary content-based instruction.

However, a potential concern for the present project is the adequacy of the time given for practicing the four skills. Students are supposed to practice these skills on a daily basis as they are integrated into all the lessons. Yet, the question that poses itself here is whether or not this practice is enough for students. This issue can be a diagnostic area for continuous research during the teaching and learning of this course. A formative type of evaluation could be conducted 
to speculate on students' progress in language skills. Diagnostic quizzes can provide a good sampling of the problematic aspects of concern. Interviews could be an informative resource that could reflect back the amount of improvement on the part of students language abilities. The instructor of the course, therefore, needs to adapt and modify course components and mechanisms accordingly via reassessing the types of activities used, the amount of practice and skills that should be addressed more, pair/group work configurations, etc.

To conclude, it is the responsibility of all concerned to support and appreciate the use of preliminary academic training for Saudi students who are to be sent abroad to pursue their higher studies. Such communicative language preparation would result in lesser expected fears and/ or inconveniences in the new environment that Saudi students might have experienced. Reflecting on the experiences of current Saudi students' enrolled in American universities would also help find out the obstacles that hinder students' academic learning and any potential risks that might cause a withdrawal from social and cultural life on and off campus.

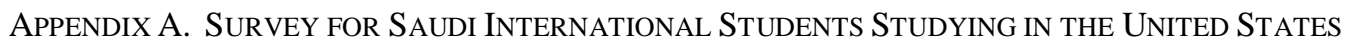

How prepared did you feel for the following tasks upon arrival to the U.S.?

Please check the box on the right that most appropriately answers the statements on the left.

\section{Under-prepared Somewhat prepared Well-prepared}

1. Understanding American English pronunciation.

2. General listening comprehension.

3. Note-taking.

4. Participating in class discussions.

5. Communicating with classmates outside of class

6. Communicating with professors in or

7. Communicating with others in service encounters (for example, at the supermarket, cafeteria, etc.)

8. Giving directions.

9. Writing paragraphs and essays.

10. Writing introductions and conclusions.

11. Synthesizing information from different one source.

12. knowledge of Vocabulary.

13. Expressing your views in writing.

14. Expressing your views in speech.

15. Reading quickly.

16. Reading comprehension.

17. Grammar in general

18. Other, please specify
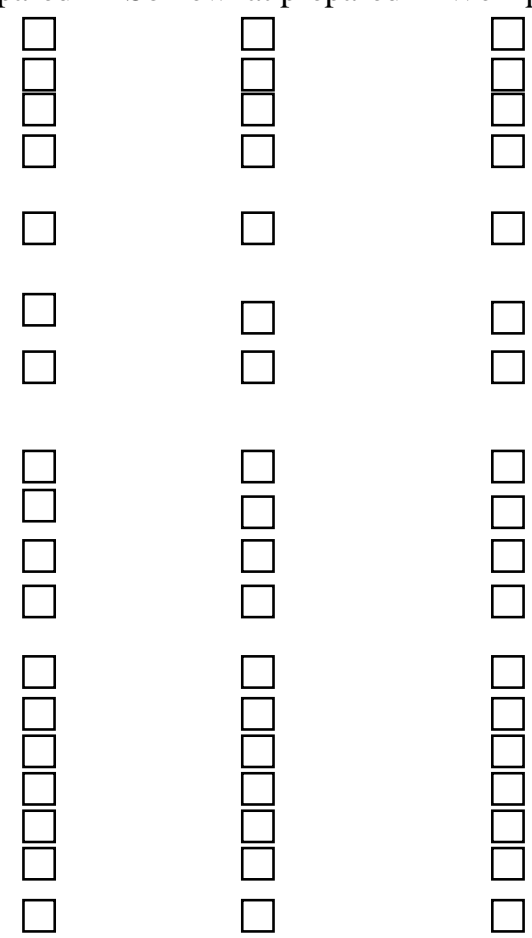

ApPendix B. Survey of English KNOWLedge, Experiences, ANd PREFERENCES

Please check the appropriate choice in response to the question.

1. How long have you been studying English?

Less than a year 1-2 years

2-4 years

More than 4 years

2. Where did you study English language? (Check all that apply)

In high school

With a private tutor

In a private institute

At the university

Abroad _ Other, please specify

3. How many hours per week of study were there?

1-2 hours

2-4 hours

4-6 hours

6-8 hours

8-10 hours

More than 10

4. What type of instructions did your English courses include? (Check all that apply)

Grammar

Reading

Writing

Speaking Listening

Teacher to student interaction

Student to student activities

5. In what areas do you feel most confident in using English? (Check all that apply)

Grammar

Reading

Writing 
Speaking _ Listening

6. What skills of English would you like to concentrate on in this language class? (Check all that apply)

Grammar _ Reading _ Writing

Speaking _ Listening

Please rate on a scale of 1 to 5 ( 1 meaning not very good and 5 being very good).

7. How good do you feel at doing the following activities in English?

Reading a popular magazine ___ Reading a textbook

Writing a letter to a friend____ Understanding a movie

Holding a conversation with and understanding native speakers

Answer the following question as thoroughly as possible.

8. Have you ever studied or traveled in an English speaking country before? If so, where and for how long?

\section{APPENDiX C. SAMPLE LESSON PLAN}

Brief description of classroom setting: An EAP Language classroom at Jazan university in Saudi Arabia. Content/skills-based/lexical syllabus. Intermediate-level students.

Pre-lesson description

Overview of lesson goals: By the end of this lesson, students will...

- become familiar with authentic university website discourse;

- learn about the organization of expository text

- learn to paraphrase material they have read.

Materials to take to class: Example of "office of International students" university website prose (see Appendix D),

Equipment needed for class: none

Assignments to collect from students: none

Warm-up: (5-7 minutes)

Purpose: To foster students think about the types of tasks they will need to accomplish at the university setting abroad;

To prepare the students for the upcoming activity;

To practice necessary skills for classroom discussion.

Procedures:

1. Ask students to name different daily tasks that they may need to accomplish when studying abroad. Write the tasks on the board.

2. Ask students how they feel about doing these tasks in an unfamiliar environment, and why.

3. Ask students how could these tasks be made easier.

Activity 1: Sequencing activity (25 minutes)

Purpose: To introduce students to an example of the organizational structure of expository prose in a university website.

To improve students' reading skills by making them aware of this kind of organization

To expose students to a type of discourse that they will need to use in their English writing assignments

To give students the opportunity to interact orally in English while discussing the activity.

Procedures:

1. Ask students to organize themselves in groups of two.

2. Hand in the university website prose clippings.

3. Give students time to read over all the clippings.

4. Ask students to sequence the clippings in the appropriate order.

5. Ask for two or three volunteer groups to read their sequences to the class.

6. Hand out the original website prose and ask for volunteer to read aloud.

a. Identify the group that had correct sequencing, and ask them why they arranged it the way they did.

b. Discuss structures of organization (e.g., intro., body, conclusion)

Activity 2: Paraphrasing (20-25 minutes)

Purpose: To practice paraphrasing

To interact orally in English as they explain their reasons for paraphrasing as they did.

To practice using a thesaurus.

Procedures:

1. Teacher writes few examples of paraphrasing on the board.

a. Ask if there are any questions.

b. Show how a thesaurus can be used for this task.

2. Ask students to continue with the same text, in the same groups. 
3. Ask students to discuss paraphrasing options with partners.

4. Ask students to present their examples of paraphrasing to the class.

a. Write good examples of paraphrasing on board.

Closure (4-5 minutes)

Purpose: To review aspects of the organization of expository prose

To review aspects of paraphrasing;

1. Ask students what the organization of the website prose was. (Try to elicit ideas using the following patterns)

a. Brief introduction which frames topic.

b. Body with specific details.

c. Conclusion to some up main points of prose.

2. Ask students: "Why do we need to learn to paraphrase?"

HW assignment: Think of 10 words from the texts you studied in class and find synonyms for them in the thesaurus.

\section{APPENDIX D}

CISP provides services to international students through International Orientation, International Student Services, as well as domestic and international students through Education Abroad and the National Student Exchange. The Center also provides support and guidance to faculty and staff in their CSU-related international endeavors. The Center is also the administrative home of the University's Fulbright Program and the starting point for all CSU international agreements, linkages, and partnerships.

It also provides international students with an American partner who acts as a contact person. This person is someone who can offer international students help with opening bank accounts, buying used bicycles, finding inexpensive restaurants, registering for courses and assisting with school work to name a few. It's a great way to make friends with Americans and members of the Flagstaff community.

International students have many opportunities for both academic and personal growth at Cleveland State University. Whether you are looking for an undergraduate ( freshman, transfer ), graduate or doctoral degree, or for English language courses, CSU offers a wide range of resources and opportunities, as well as an ideal environment to help you succeed and achieve your academic goals.

International students may also become involved in campus life through a variety of student organizations and university programs that include cultural activities, sports, the arts and social events. Our staff is especially qualified to meet the varied needs of all international students at the undergraduate and graduate level.

Contact us or visit us in Main Classroom \#412

Our office hours are Monday - Friday, 8:00am - 5:00pm (EST).

\section{REFERENCES}

[1] Brinton, D. M., Snow, M. A. and Wesche, M. B. (1989). Content-based second language instruction. Boston: Heinle and Heinle Publishers.

[2] Brinton, D. M. (2007). Two for one-Language-enhanced content instruction in English for academic purposes. In Teaching English for specific purposes: Meeting our learners' needs (pp. 1-16). Alexandria, VA: TESOL.

[3] Coyle, D., Hood, P., \& Marsh, D. (2010). CLIL: Content and language integrated learning. Cambridge, England: Cambridge University Press.

[4] Drake, S. M., Burns, R. C. (2004). Meeting standards through integrated curriculum. Alexandria, VA. Association for Supervision and Curriculum Development.

[5] Early, M. (2001). Language and content in social practice: A case study. The Canadian Modern Language Review, 58(1), 156179

[6] Ellis, R., (2003). Task-based language learning and teaching, Oxford: Oxford University Press.

[7] Farrell, T. S. C. (2012). Reflecting on reflective practice: (Re)Visiting Dewey and Schön. TESOL Journal 3 (1): 7-16.

[8] Fogarty, R. \& Stoehr, J. (1995). Integrating curricula with multiple intelligences: Teams, themes, and threads. Palatine, IL: Skylight.

[9] Kumaravadivelu, B. (2001). Toward a postmethod pedagogy. TESOL Quarterly 35 (4): 537-560.

[10] Liuoliene, A. and Metiuniene, R. (2006). Second Language Learning Motivation. Santalka, Filologija, Edukologija 14 (2):9398.

[11] MacMath, S., Wallace, J., \& Chi, X. (2009). Curriculum integration: Opportunities to maximize assessment as, of, and for learning. McGill Journal of Education, 44, 451-466.

[12] Mohan, B. (1986). Language and content. Reading, MA: Addison Wesley.

[13] Oxford, R.L. (2001). "Language learning strategies" in R. Carter \& D. Nunan. (Eds.). The Cambridge guide to teaching English to speakers of other languages (pp.166-172). UK: Cambridge University Press

[14] Paterson, J. (2003). Curriculum integration in a standards-based world. Middle ground: The Magazine of Middle Education, $7(1), 10-12$.

[15] Pawan, F., \& Ortloff, J. H. (2011). Sustaining collaboration: English-as-a-second-language, and content-area teachers. Teaching and Teacher Education, 27, 463-471.

[16] Pring, R. (2006). Curriculum integration. Journal of Philosophy of Education, 5(2), 170-200. 
[17] Reynolds, K. M. (2015). Approaches to inclusive English classrooms: A teacher's handbook for content-based instruction. Bristol, England: Multilingual Matters.

[18] Richards, J. C. (1990). The language teaching matrix. Cambridge: Cambridge University Press

[19] Richards, J. C. (2001). Curriculum development in language teaching. Cambridge University Press: New York.

[20] Richards, J. C. \& Rodgers, T. S. (2001). Approaches and methods in language teaching (2nd ed.). Cambridge, UK: Cambridge University Press.

[21] Stoller, F. (1999). Time for change: a hybrid curriculum for EAP programs. TESOL Journal, 8(10), 9-13.

[22] Swan, M., (2005). Legislation by hypothesis: The case of task-based instruction, Applied Linguistics, 26(3), $376-401$.

[23] Tarone, E. (1989). Teacher-executed needs assessment: Some suggestions for teachers and program administrators. MinneTESOL Journal 7: 39-48.

[24] Valeo, A. (2013). The integration of language and content: Form-focused instruction in a content based language program. The Canadian Journal of Applied Linguistics, 16(1), 25-50

[25] Wesche, M. B., \& Skehan, P. (2002). Communicative, task-based, and content-based language instruction. In R. B. Kaplan (Ed.), The Oxford handbook of applied linguistics (pp. 207-228). Oxford, UK: Oxford University Press.

[26] Wesche, M. B. (2010). Content-based second language instruction. In R. Kaplan (Ed.), The Oxford handbook of applied linguistics (2nd ed., pp. 275-293). Oxford, England: Oxford University Press.

[27] West, R. (1997). Needs analysis: State of the Art. In Howard, R., \& Brown, G. (Eds.), Teacher education for LSP (pp. 68-79). Clevedon, UK: Multilingual Matters.

Sami Ali Al-wossabi is an associate professor of Applied Linguistics at the English department, Jazan University, Saudi Arabia. $\mathrm{He}$ is currently teaching English language courses in Applied Linguistics, Sociolinguistics and Language Acquisition. He has also written articles on different research topics. His main areas of interest include Task-based language teaching (TBLT), communicative language teaching (CLT), computer assisted language learning (CALL) and second language acquisition (SLA). 